\title{
Clinical Trial of Measles and Rubella Combined Vaccine Produced by POLYVAC in Vietnam
}

\author{
Nguyen Dang Hien', Nguyen Thuy Huong1, Ngo Thu Huong1, Pham Thi Phuong Thao1, \\ Dinh Hong Duong ${ }^{2}$, Nguyen Xuan Dong2 ${ }^{2}$ Tomio Lee ${ }^{3}$, Takashi Ito ${ }^{4}$, Tetsuo Nakayama ${ }^{*}$ \\ ${ }^{1}$ Center for Research and Production of Vaccines and Biologicals (POLYVAC), Hanoi, Vietnam \\ ${ }^{2}$ Military Academy of Medicine, Hanoi, Vietnam \\ ${ }^{3}$ Kitasato Vaccine Plant, Kitasato Daiichi Sankyo Vaccine, Saitama, Japan \\ ${ }^{4}$ Laboratory of Viral Infection I, Kitasato Institute for Life Sciences, Tokyo, Japan \\ Email: *tetsuo-n@lisci.kitasato-u.ac.jp
}

How to cite this paper: Hien, N.D., Huong, N.T., Huong, N.T., Thao, P.T.P., Duong, D.H., Dong, N.X., Lee, T., Ito, T. and Nakayama, T. (2018) Clinical Trial of Measles and Rubella Combined Vaccine Produced by POLYVAC in Vietnam. Open Journal of Pediatrics, 8, 178-188.

https://doi.org/10.4236/ojped.2018.82020

Received: May 14, 2018

Accepted: June 18, 2018

Published: June 21, 2018

Copyright $\odot 2018$ by authors and Scientific Research Publishing Inc. This work is licensed under the Creative Commons Attribution International License (CC BY 4.0). http://creativecommons.org/licenses/by/4.0/

\section{Open Access}

\begin{abstract}
A clinical trial of measles and rubella combined vaccine (MR: MRVAC) produced by POLYVAC was conducted in Vietnam in 2016. A total of 756 subjects were enrolled, and 504 were allocated to MRVAC and 252 to control MR vaccine groups. Paired sera were obtained in 733 , and the number of subjects was 403 aged $1-2$ years, 164 aged 2 - 18 years, and 166 aged $18-45$ years. Antibodies against measles and rubella viruses were evaluated by EIA. Most subjects had been immunized with a single dose of Expanded Programme on Immunization (EPI) measles vaccine at 9 months of age. Only 41 of 403 subjects aged $1-2$ years were negative for measles antibody before vaccination, and all became seroconverted. A serological response of more than a 2 -fold increase against measles was noted in 214 (47\%, 95\% CI; $42.4 \%-51.6 \%)$ of 458 initially seropositive individuals immunized with MRVAC and 65 (28\%, 95\% CI; $22.3 \%-33.8 \%$ ) of 234 in the control group, and geometric mean titer (GMT) after vaccination was $2^{5.49-5.60}$ in MRVAC and $2^{5.03-5.24}$ in control group. Seroconversion against rubella virus after immunization with MRVAC was noted in 267 (98.5\%, 95\% CI; 97.1\% - 100\%) of 271 initially seronegative subjects, similar to that after immunization with control group. GMT after immunization with MRVAC was $2^{4.88-5.11}$ significantly lower than that after immunization with control vaccine $\left(2^{5.59-5.80}\right)$. Most subject $\geq 2$ years of age had rubella antibody because of MR vaccination campaign and no significant serological response was observed in initially seronegatives. MRVAC was highly immunogenic and safe vaccine and the domestic production of MR vaccine would contribute to realizing the goal of eliminating measles and rubella.
\end{abstract}

\section{Keywords}

Measles Vaccine, Rubella Vaccine, MR Combined Vaccine, Elimination of 
Measles and Rubella

\section{Introduction}

Many kinds of live attenuated measles vaccine strain have been used, and Moraten, Schwarz, Edmonston Zagreb, and AIK-C strains were developed from the Edmonston strain, isolated from peripheral blood of measles patient in 1954 . They were adapted through extensive passages in chicken embryo fibroblasts (CEF) [1]. Before 2000, measles deaths were estimated at 870,000 every year, and the WHO and UNICEF implemented the Expanded Programme on Immunization (EPI) in 1974 to increase the vaccine immunization rates of infants under one year of age, declaring measles eradication to be the most practical strategy [2]. Initially, the target year of measles eradication was 2010, but it was not realized. Several outbreaks were reported in the UK, France, and Germany in the E.U. in 2011 [3] [4]. Although 2015 was a renewed target year, several imported cases were reported in the U.S., E.U., and Japan from Africa and Southeast Asia, where measles is still prevalent and not under control. Measles cases were reported in many countries and 134,200 measles-related deaths were estimated in the world in 2015 with approximately $85 \%$ single-dose vaccine coverage [5]. The WHO recommended a two-dose immunization schedule in countries where the immunization rate for the first dose was $>95 \%$ [5].

Rubella is not serious febrile illness with systemic rash, but it causes the severe congenital rubella syndrome (CRS) when pregnant women are infected in the first trimester period. Rubella virus was isolated in 1962. The RA27/3 strain was established through serial passages in human diploid cells at a lower temperature, which has been widely used [6]. Rubella vaccine was not included in the EPI vaccines until recently, and rubella monovalent, $M R$, and $M M R$ vaccine are recommended in EPI vaccine for reducing the number of CRS. Although the number of patients with measles decreased through the EPI action, more than 100,000 cases with CRS were estimated, and therefore the Measles and Rubella Initiative was launched to eradicate measles-related deaths and births with CRS. The target has been renewed to achieve measles and rubella elimination in at least five WHO regions by 2020 [5].

The WHO summarized the status of the measles and rubella outbreaks and recommended rubella together with measles vaccination. The Ministry of Health in Vietnam asked JICA to support producing an MR combined vaccine, considering the benefits of a combined immunization strategy. POLYVAC successfully produced measles vaccine and the urgent supply of 5 million doses of monovalent measles vaccine to prevent a further expansion of measles outbreak in 2014 [7]. Technical transfer to produce MR vaccine started in 2013 using rubella Takahashi and measles AIK-C strains, and the results of a phase III clinical study are presented in this report. 


\section{Materials and Methods}

\subsection{Vaccines and Immunization Schedule}

A randomized clinical trial was conducted using MRVAC produced by POLYVAC in Hanoi, Vietnam, containing the AIK-C measles and Takahashi Rubella vaccine strains $\geq 10^{3} \mathrm{pfu} / \mathrm{dose}$ [8] [9], and MR control vaccine produced by the Serum Institute of India, containing Edmonston-Zagreb and RA27/3 strains. Each vaccine component contained $\geq 10^{3} \mathrm{CFU}$. The study design was approved by the Ethics Committee of Vietnam Ministry of Health.

The purpose of the study was to assess the non-inferiority of MRVAC within $10 \%$ difference of the seroconversion rates for measles and rubella. Healthy children and adults aged 1 to $<45$ years were included. The main exclusive criteria implied severe acute illness, any history of anaphylaxis after immunization with similar vaccine components, and any past medical history of the illness related to immunological disorders. Clinical trial was conducted in two different sites, Hoa Binh and Ha Nam provinces, from April to July 2016. A total of 756 subjects were enrolled, and 504 were allocated to the MRVAC group and 252 to the control group, giving a ratio of 2:1, with three different age groups: 420 at $1-2$ years, 168 at $2-18$ years, and 168 at $18-45$ years. The details of the number of the subjects in the different age groups are shown in Table 1. The male/female ratio was 217/287 in the MRVAC and 160/92 in the control group. Paired sera were obtained from 733 and the number of subjects was 403 at $1-2$ years, 164 at $2-18$ years, and 166 at $18-45$ years.

\subsection{Serological Study}

Paired sera were not obtained from 23 recipients out of 756 because of refusal of blood taking at the second visit and a total of 733 paired sera were examined for serological responses. Vaccine efficacy was evaluated by EIA antibodies, using measles and rubella EIA kits (Denka Seiken, Tokyo, Japan). Briefly, serum samples were diluted to 1:200 and all procedures followed the instruction manual. EIA titers are expressed as EIA units, referring to the standard sera (Denka

Table 1. Age distribution of recipients of MRVAC and control vaccine.

\begin{tabular}{ccccccccc}
\hline $1-2$ years & \multicolumn{2}{l}{ MRVACControl } & $2-18$ years & MRVAC & Control & $18-45$ years & MRVAC & Control \\
\hline $12-<14 \mathrm{M}$ & 49 & 25 & $2-<6 \mathrm{Y}$ & 41 & 20 & $18-<27 \mathrm{Y}$ & 38 & 15 \\
$14-<16 \mathrm{M}$ & 63 & 36 & $6-<10 \mathrm{Y}$ & 26 & 14 & $27-<36 \mathrm{Y}$ & 46 & 32 \\
$16-<18 \mathrm{M}$ & 75 & 34 & $10-<14 \mathrm{Y}$ & 34 & 16 & $36-45 \mathrm{Y}$ & 28 & 9 \\
$18-<20 \mathrm{M}$ & 49 & 23 & $14-<18 \mathrm{Y}$ & 11 & 6 & $18-45 \mathrm{Y}$ & 112 & 56 \\
$20-<22 \mathrm{M}$ & 31 & 16 & $2-<18 \mathrm{Y}$ Total & 112 & 56 & & & \\
$22-<24 \mathrm{M}$ & 13 & 6 & & & & & & \\
$1-<2$ Y Total & 280 & 140 & & & & & & \\
\hline
\end{tabular}


Seiken, Tokyo, Japan). EIA units $<4$ are considered as seronegative. Seroconversion was defined as a two-fold increase in the titers from just before to $6-8$ weeks after immunization.

\subsection{Assessment of Adverse Reactions}

Adverse reactions were collected to memorize the diary to check the occurrence of solicited symptoms until 4 weeks after vaccination.

\subsection{Statistical Analysis}

For statistical analysis, seroconversion rate was assessed by chi-square method and Welch's t test to assess the significance of GMT. Significance was defined as $\mathrm{p}<0.05$, using STAT I software.

\section{Results}

\subsection{Serological Response against Measles Virus}

Among the 756 subjects immunized, paired sera were obtained from 733 subjects, shown in Table 1 . The distribution of the number of the subjects was 403 at 1 - 2 years, 164 at $2-18$ years, and 166 at 18 - 45 years. Most subjects had already been immunized with a single dose of the EPI measles vaccine at 9 months of age and supplemental immunization with MR vaccine at 18 months of age, and only 41 subjects were negative for measles antibody before vaccination. 30 were MRVAC group and 11 in the control groups. The results of serological response against measles virus are shown in Table 2 . All subjects of initially seronegatives became seroconverted, and GMT after immunization with MRVAC was $2^{(5.35: 95 \% \mathrm{CI} ; 5.05-5.65)}$, being significantly higher than $2^{(4.71: 95 \% \mathrm{CI} ; 4.20-5.23)}$ in the control group. A total of 692 subjects were initially seropositive against measles virus and 458 were MRVAC group and 234 in the control group. Seroconversion rate was 214/458 (47\%, 95\% CI; 42.4 - 51.6\%) in MRVAC group, which was significantly higher than in the control group 65/234 (28\%, 95\% CI; 22.3\% - 33.8\%). GMT after immunization with MRVAC was $2^{(5.55: 95 \% \mathrm{CI} ; 5.49-5.60)}$, showing significant higher titers of $2^{(5.14: 95 \% \mathrm{CI} ; 5.03-5.24)}$ in the control group.

Serological response of the subjects initially seropositive was analyzed in the different populations and the results are shown in Figure 1. A higher serological response showing more than 2-fold increase was noted in121 (47.6\%) of 254 subjects at 1 - 2 years immunized with MRVAC and in 41 (31.3\%) of 131 in the control group. The seroconversion rate was higher in the MRVAC than control groups for each age group: in the group aged 2 - 18 years, 68/100 (68\%) for MRVAC and $16 / 49$ (32.7\%) for the control group, in the group aged $18-45$ years, 25/104 (24.0\%) for MRVAC and 8/54 (14.8\%) for the control group. GMT was $2^{(4.52: 95 \% \text { CI; 4.42-4.61) }}$ before vaccination and $2^{(5.55: 95 \% \text { CI; 5.49-5.60) }}$ after immunization with MRVAC and was $2^{(4.58: 95 \% \text { CI; 4.44-4.73) }}$ before vaccination and $2^{(5.14: 95 \% \text { CI; 5.03-5.24) }}$ after immunization with the control vaccine. MRVAC induced significantly 
Table 2. Serological responses against measles virus in initially seronegative and seropositive subjects.

\begin{tabular}{|c|c|c|c|c|c|c|c|}
\hline & & & $\mathrm{n}$ & Seroconversion & Mean* & $1.0 \mathrm{SD}$ & $95 \% \mathrm{CI}^{*}$ \\
\hline \multirow{2}{*}{$\begin{array}{c}\text { Measles } \\
\text { pre (-) }\end{array}$} & MRVAC & post & 30 & $30 / 30(100 \%)$ & 5.35 & 0.81 & $5.05-5.65$ \\
\hline & Control & post & 11 & $11 / 11(100 \%)$ & 4.71 & 0.77 & $4.20-5.23$ \\
\hline \multirow{4}{*}{$\begin{array}{c}\text { Measles } \\
\text { pre }(+)\end{array}$} & \multirow[b]{2}{*}{ MRVAC } & pre & 458 & & 4.52 & 1.060 & $4.42-4.61$ \\
\hline & & post & 458 & $\begin{array}{c}214 / 458(47 \%) \\
95 \% \mathrm{CI} ; 42.4 \%-51.6 \%\end{array}$ & 5.55 & 0.604 & $5.49-5.60$ \\
\hline & \multirow[b]{2}{*}{ Control } & pre & 234 & & 4.59 & 1.146 & $4.44-4.73$ \\
\hline & & post & 234 & $\begin{array}{c}65 / 234(28 \%) \\
95 \% \text { CI; } 22.3 \%-33.8 \%\end{array}$ & 5.14 & 0.075 & $5.03-5.24$ \\
\hline
\end{tabular}

*: Antibody titers of measles virus after immunization shown as $2^{\text {n }}$.
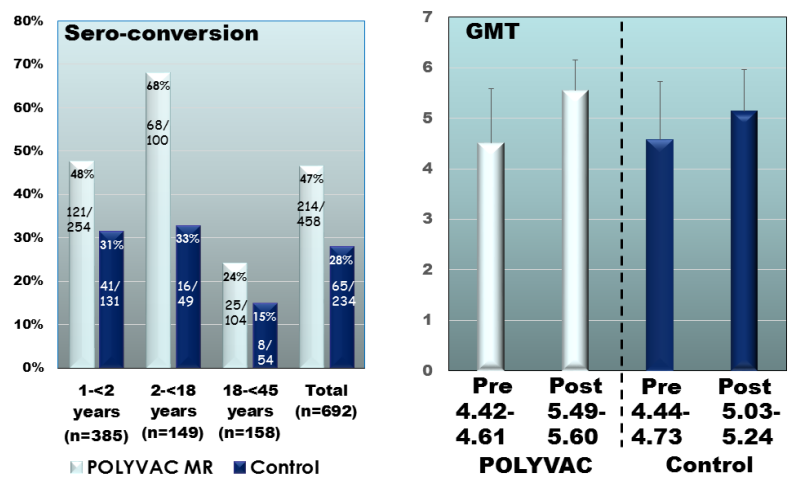

Figure 1. Seroconversion rates in different age groups in initially seropositives and GMT before and after immunization.

stronger serological responses than the control vaccine.

\subsection{Serological Response against Rubella Virus}

Rubella vaccine was not included in EPI vaccines before 2014, but MR vaccine produced by the Serum Institute of India was administered for immunization campaign as the second dose of the measles component at 18 months of age from 2015. Most subjects aged 1 - 2 years were seronegative for rubella virus, and most subjects over 2 years of age were seropositive. Seroconversion for rubella virus is shown in Table 3. Seroconversion after immunization with MRVAC was noted 267 (98.4\%, 95\% CI; 97.1\% - 100\%) of the 271 initially seronegative subjects, similar to that after the control vaccine, in 139 (99.2\%, 95\% CI; $98.0 \%-100 \%$ ) of 140 . Including subjects of initially seronegative aged $>2$ years, GMT after immunization with MRVAC was $2^{(5.00: 95 \% \text { CI; 4.88-5.11) }}$, being lower than that after immunization with control vaccine of $2^{(5.69: 95 \% \text { CI 5.59-5.80). }}$

Seroconversion rates against rubella virus are also investigated for initially seropositive subjects immunized with MRVAC and control groups. Most seropositives had high levels of rubella antibodies $\geq 2^{5}$ before immunization. A more than 2-fold higher serological response was rarely observed in either group. No significant increase was demonstrated in both vaccine groups. 
Table 3. Serological responses against rubella virus in initially seronegative and positive subjects.

\begin{tabular}{|c|c|c|c|c|c|c|c|}
\hline & & & $\mathrm{n}$ & Seroconversion & Mean & $1.0 \mathrm{SD}$ & $95 \% \mathrm{CI}$ \\
\hline \multirow{2}{*}{$\begin{array}{l}\text { Rubella } \\
\text { pre (-) }\end{array}$} & MRVAC & post & 271 & $\begin{array}{c}267 / 271(98.5 \%) \\
95 \% \text { CI; } 97.1 \%-100 \%\end{array}$ & 5.00 & 0.96 & $4.88-5.11$ \\
\hline & Control & post & 140 & $\begin{array}{c}139 / 140(99.3 \%) \\
95 \% \text { CI; } 98.0 \%-100 \%\end{array}$ & 5.69 & 0.64 & $5.59-5.80$ \\
\hline \multirow{4}{*}{$\begin{array}{l}\text { Rubella } \\
\text { pre }(+)\end{array}$} & & pre & 217 & & 5.65 & 0.709 & $5.55-5.74$ \\
\hline & MRVAC & post & 217 & $\begin{array}{c}1 / 217(0.5 \%) \\
95 \% \mathrm{CI} ; 0 \%-1.4 \%\end{array}$ & 5.64 & 0.663 & $5.56-5.73$ \\
\hline & & pre & 105 & & 5.62 & 0.774 & $5.47-5.77$ \\
\hline & Control & post & 105 & $\begin{array}{c}5 / 105(4.8 \%) \\
95 \% \text { CI; } 0.8 \%-9.2 \%\end{array}$ & 5.82 & 0.550 & $5.71-5.92$ \\
\hline
\end{tabular}

\subsection{Safety Profile}

A total of 756 subjects were enrolled to analyze the safety issue: 504 for MRVAC and 252 for the control vaccine. The incidence of local reactions such as pain, eruption, and swelling are shown in Table 4. Eruption was demonstrated in 13/280 (4.6\%, 95\% CI; 2.2\% - 7.1\%) of subjects aged $1-2$ years immunized with MRVAC, being lower than the $15 / 140(10.7 \%$, 95\% CI; 5.6\% -15.8\%) after immunization with the control vaccine. No significant difference was observed in the occurrence of local pain and swelling at the injection site.

The incidence of systemic adverse events is shown in Table 5. No significant difference was observed in the incidence of systemic adverse events, febrile illness, discomfort, cough, diarrhea, or sore throat between the MRVAC and control groups

Two serious cases were reported. Case No. 1 was a two-year-old boy, who complained of fever and acute abdominal pain six days after immunization with MRVAC. He was diagnosed with appendicitis and recovered after appendectomy. Case No. 2 was a 27-year-old female, who complained of localized pain, redness, and swelling at the injection site. She was diagnosed with a subcutaneous abscess and recovered after incision and chemotherapy. They were discussed by the Committee for Judgement of Adverse Events organized in the vaccine's clinical trial and were judged as incidental events not-related to the immunization.

\section{Discussion}

Measles is a life-threatening illness and measles infection causes transient immunological disorders resulting in secondary infections, such as pneumonia and diarrhea. Malnourished children in developing countries are more likely to have severe complications: blindness caused by deficiency of vitamin A, delayed development, and neurological sequelae. Rubella is a mild illness but cause CRS when pregnant women were infected with rubella virus at first trimester gestational period. Therefore, measles and rubella infections are still major infectious diseases threatening children's health. The Measles and Rubella Initiative was 
Table 4. Incidence of local adverse events within 7 days after immunization.

\begin{tabular}{|c|c|c|}
\hline \multicolumn{3}{|c|}{ Local pain at injection site } \\
\hline Age groups & MRVAC & Control \\
\hline $1-2$ years & $9 / 280(3.2 \%)(95 \%$ CI; $1.1 \%$ - 5.23\%) & 5/140 (3.6\%) (95\% CI; $0.51 \%$ - 6.7\%) \\
\hline $2-18$ years & $0 / 112$ & $0 / 56$ \\
\hline $18-45$ years & $1 / 112(0.9 \%)(95 \% \mathrm{CI} ; 0 \%-2.7 \%)$ & $0 / 56$ \\
\hline Total & $10 / 504(2.0 \%)(95 \%$ CI; $0.8 \%-3.2 \%)$ & $5 / 252(2.0 \%)(95 \%$ CI; $0.3 \%$ - 3.7\%) \\
\hline \multicolumn{3}{|l|}{$\begin{array}{c}\text { Eruption at } \\
\text { injection site }\end{array}$} \\
\hline Age groups & MRVAC & Control \\
\hline $1-2$ years & $13 / 280(4.6 \%)(95 \%$ CI; $2.2 \%-7.1 \%)$ & $15 / 140(10.7 \%)(95 \% \mathrm{CI} ; 5.6 \%-15.8 \%)$ \\
\hline $2-18$ years & $1 / 112(0.9 \%)(95 \%$ CI; $0 \%-2.7 \%)$ & $2 / 56$ (3.6\%) (95\% CI; 0\% - 8.5\%) \\
\hline $18-45$ years & $1 / 112(0.9 \%)(95 \% \mathrm{CI} ; 0 \%-2.7 \%)$ & $0 / 56$ \\
\hline Total & $15 / 504(3.0 \%)(95 \%$ CI; $1.5 \%$ - 4.5\%) & $17 / 252(6.7 \%)(95 \%$ CI; $3.6 \%$ - 9.8\%) \\
\hline \multicolumn{3}{|l|}{$\begin{array}{l}\text { Swelling at } \\
\text { injection site }\end{array}$} \\
\hline Age groups & MRVAC & Control \\
\hline $1-2$ years & $2 / 280(0.7 \%)(95 \%$ CI; $0 \%-1.7 \%)$ & $2 / 140(1.4 \%)(95 \%$ CI; $0 \%-3.4 \%)$ \\
\hline $2-18$ years & $1 / 112(0.9 \%)(95 \%$ CI; $0 \%-2.7 \%)$ & $1 / 56(1.8 \%)(95 \%$ CI; $0 \%-5.3 \%)$ \\
\hline $18-45$ years & $1 / 112(0.9 \%)(95 \% \mathrm{CI} ; 0 \%-2.7 \%)$ & $2 / 56(3.6 \%)(95 \%$ CI; $0 \%-8.48 \%)$ \\
\hline Total & $4 / 504(0.8 \%)(95 \% \mathrm{CI} ; 0 \%-1.6 \%)$ & $5 / 252(1.9 \%)(95 \%$ CI; $0.2 \%-3.6 \%)$ \\
\hline
\end{tabular}

launched in 2001, and measles still killed an estimated 115,000 children and CRS affected 100,000 births every year [5] [10].

In Vietnam, approximately 1.5 million babies are born each year. A nationwide supplementary immunization campaign for children aged 9 months to 9 years was conducted several times in the north, south, and highlands of Vietnam from 2002 to 2003. The number of reported cases of measles was reduced to 2245 cases in 2003 after the introduction of a measles vaccine campaign. Vaccine coverage at 9 months of age was more than $95 \%$, with an approximately $90 \%$ seroconversion rate. A two-dose strategy of measles immunization was implemented in Vietnam at the age of 9 - 11 months and 18 months since 2006. Despite improving vaccination coverage, rapid measles resurgence was observed in 2005-2010 and 2014 [11] [12] [13]. Vaccine coverage of the first dose was estimated approximately at $85 \%$ in 2011-2014, but the coverage differed depending on the ethnic minority, socio-economic and education backgrounds [14]. The two-dose routine measles vaccine schedule with supplemental immunization campaigns requires many doses of the measles vaccine. The Japan International Cooperation Agency (JICA) and Kitasato Daiichi Sankyo Vaccine (KDSV) started the two-step technical transfer of the measles vaccine production project in 2006, with the first step being the production of final products using imported bulk materials from Kitasato Institute, Tokyo, Japan, and the second step being 
Table 5. Incidence of systemic adverse events within 28 days after immunization.

\begin{tabular}{|c|c|c|c|c|c|}
\hline Fever & & & Cough & & \\
\hline Age groups & MRVAC & Control & Age groups & MRVAC & Control \\
\hline $1-2$ years & $27 / 280(9.6 \%)$ & $11 / 140(7.9 \%)$ & 1 - 2 years & $11 / 280(3.9 \%)$ & $5 / 140(3.6 \%)$ \\
\hline $2-18$ years & $3 / 112(2.7 \%)$ & $1 / 56(1.8 \%)$ & $2-18$ years & $1 / 112(0.9 \%)$ & $0 / 56$ \\
\hline $18-45$ years & $3 / 112(2.7 \%)$ & $1 / 56(1.8 \%)$ & $18-45$ years & $1 / 112(0.9 \%)$ & $0 / 56$ \\
\hline Total & $\begin{array}{c}33 / 504(6.5 \%) \\
(95 \% \text { CI; } 4.4 \%-8.7 \%)\end{array}$ & $\begin{array}{c}13 / 252(5.2 \%) \\
(95 \% \text { CI; } 2.5 \%-7.9 \%)\end{array}$ & Total & $\begin{array}{c}13 / 504(2.6 \%) \\
(95 \% \text { CI; } 1.2 \%-4.0 \%)\end{array}$ & $\begin{array}{c}5 / 252(2.0 \%) \\
(95 \% \text { CI; } 0.3 \%-3.7 \%)\end{array}$ \\
\hline Discomfort & & & Sore throat & & \\
\hline Age groups & MRVAC & Control & Age groups & MRVAC & Control \\
\hline 1 - 2 years & $20 / 280(7.1 \%)$ & $10 / 140(7.1 \%)$ & $1-2$ years & $6 / 280(2.1 \%)$ & $2 / 140(1.4 \%)$ \\
\hline $2-18$ years & $1 / 112(0.9 \%)$ & $0 / 56$ & $2-18$ years & $1 / 112(0.9 \%)$ & $0 / 56$ \\
\hline $18-45$ years & $1 / 112(0.9 \%)$ & $0 / 56$ & $18-45$ years & $1 / 112(0.9 \%)$ & $0 / 56$ \\
\hline Total & $\begin{array}{c}22 / 504(4.4 \%) \\
(95 \% \text { CI; } 2.6 \%-6.2 \%)\end{array}$ & $\begin{array}{c}10 / 252(4.0 \%) \\
(95 \% \text { CI; } 1.6 \%-6.4 \%)\end{array}$ & Total & $\begin{array}{c}8 / 504(1.6 \%) \\
(95 \% \text { CI; } 0.5 \%-2.7 \%)\end{array}$ & $\begin{array}{c}2 / 252(0.8 \%) \\
(95 \% \text { CI; } 0 \%-1.9 \%)\end{array}$ \\
\hline \multicolumn{6}{|l|}{ Diarrhea } \\
\hline Age groups & MRVAC & Control & & & \\
\hline $1-2$ years & $1 / 280(0.4 \%)$ & $3 / 140(2.1 \%)$ & & & \\
\hline $2-18$ years & $0 / 112$ & $0 / 56$ & & & \\
\hline 18 - 45 years & $0 / 112$ & $0 / 56$ & & & \\
\hline Total & $\begin{array}{c}1 / 504(0.2 \%) \\
(95 \% \mathrm{CI} ; 0 \%-0.6 \%)\end{array}$ & $\begin{array}{c}3 / 252(1.2 \%) \\
(95 \% \text { CI; } 0 \%-2.5 \%)\end{array}$ & & & \\
\hline
\end{tabular}

production from the seed strain. The results of clinical trials were reported whereby the vaccines induced higher immunogenicity in comparison with the EPI vaccine, with a low incidence of adverse reactions [15]. The domestic production of AIK-C measles vaccine was licensed in 2010. The number of patients was reduced, but a large outbreak occurred originating from the northern mountain border region. Finally, 6613 confirmed cases were reported in 2014 and the outbreak was controlled through the urgent supply of 5 million doses [16].

From January 2011 to December 2012, 424 infants suspected of having CRS were reported in Vietnam after the 2010-11 epidemic, and 292 infants were confirmed as CRS [17]. It spread to several countries [18] [19], and large outbreaks began mainly involving adult males in Japan in 2012 and continued to 2013 [20]. During the outbreak, a total of 45 patients with CRS were reported in Japan [20]. As well as rubella outbreaks, sporadic importations of measles were reported. Genotypic investigation of circulating rubella and measles viruses identified them as strains prevalent in Southeast Asia and China, with large number of reported cases [18] [19] [21].

Yet, measles and rubella can be prevented with two doses with a high benefit/cost ratio [22] [23]. Especially, Thompson and Odahowski [24] reported significantly higher costs and health consequences of measles and rubella disease than vaccine use, with the expected disability-adjusted life year (DALY) loss for 
cases of disease generally at least 100 times the loss per vaccine cost.

The global birth cohort is approximately 134 million, and 300 million doses of MR or MMR vaccines would be required. A stable supply at an affordable cost would increase vaccine coverage and contribute to measles and rubella eradication. Most vaccines in developed countries are produced in the U.S. and E.U., but recently vaccine manufacturers in developing countries began to supply the EPI vaccines [25]. The domestic capacity for vaccine production can cope with unexpected outbreaks. Regional control of measles and rubella contributes to global and not just regional health.

In the present clinical study, MR vaccine produced by POLYVAC, Vietnam, showed efficient serological response against measles and rubella. Seroconversion rate against measles virus and GMT were higher than control MR vaccine. Limitation of the present study, MR vaccine was administered to infants $>1$ year of age, assumed that MR vaccine would be used as the second dose. To simplify the immunization schedule, the immunogenicity and safety should be examined for those aged 9 months. Although small number of initially seronegative for measles was recruited, immunogenicity and safety of AIK-C measles vaccine produced by POLYVAC were proved after the licensure. Seroconversion rate against rubella virus was similar to that observed in control MR group with slightly lower GMT titers. There was no significant difference in the incidence of adverse reactions. Constant production of domestic MR vaccine would contribute to promote public health in Vietnam, and, in future, it will be shipped to Southeast Asian counties for EPI.

\section{References}

[1] Strebel, P.M., Papania, M.J., Fiebelkrorn, A.P. and Halsey, N.A. (2013) Measles vaccine. In: Plotkin, S.A., Orenstein, W.A. and Offit, P.A., Eds., Vaccines, 6th Edition, Elsevier Inc., New York, 352-387.

https://doi.org/10.1016/B978-1-4557-0090-5.00028-8

[2] Durrheim, D.N., Crowcroft, N.S. and Strebel, P.M. (2014) Measles-The Epidemiology of Elimination. Vaccine, 32, 6880-6883.

https://doi.org/10.1016/j.vaccine.2014.10.061

[3] Leslie, T.F., Delamater, P.L. and Yang, Y.T. (2018) It Could Have Been Much Worse: The Minnesota Measles Outbreak of 2017. Vaccine, 36, 1808-1810. https://doi.org/10.1016/j.vaccine.2018.02.086

[4] Carrillo-Santisteve, P. and Lopalco, P.L. (2012) Measles Still Spreads in Europe: Who Is Responsible for the Failure to Vaccinate? Clinical Microbiology and Infection, 18, 50-56. https://doi.org/10.1111/j.1469-0691.2012.03982.x

[5] WHO (2012) Global Measles and Rubella Strategic Plan: 2012-2020. World Health Organization, Geneva. https://reliefweb.int/sites/reliefweb.int/files/resources/Measles_Rubella_StrategicPla n_2012_2020.pdf

[6] Reef, S.E. and Plotkin, S.A. (2013) Rubella Vaccine. In: Plotkin, S.A., Orenstein, W.A. and Offit, P.A., Eds., Vaccines, 6th Edition, Elsevier Inc., New York, 688-717. https://doi.org/10.1016/B978-1-4557-0090-5.00038-0 
[7] Hagan, J.E., Kriss, J.L., Takashima, Y., Mariano, K.M.L., Pastore, R., Grabovac, V., Dabbagh, A.J. and Goodson, J.L. (2018) Progress toward Measles Elimination-Western Pacific Region, 2013-2017. MMWR, 67, 491-495. https://doi.org/10.15585/mmwr.mm6717a3

[8] Makino, S., Sasaki, K., Nakamura, N., Nakagawa, M. and Nakajima, S. (1974) Studies on the Modification of the Live AIK Measles Vaccine. II. Development and Evaluation of the Live AIK-C Measles Vaccine. The Kitasato Archives of Experimental Medicine, 47, 13-21.

[9] Ohtawara, M., Kobune, F., Umino, Y. and Sugiura, A. (1985) Inability of Japanese Rubella Vaccines to Induce Antibody Response in Rabbits Is due to Growth Restriction at 39 Degrees C. Archives of Virology, 83, 217-227. https://doi.org/10.1007/BF01309918

[10] Castillo-Solorzano, C., Marsigli, C., Danovaro-Holliday, M.C., Ruiz-Matus, C., Tambini, G. and Andrus, J.K. (2011) Measles and Rubella Elimination Initiatives in the Americas: Lessons Learned and Best Practices. The Journal of Infectious Diseases, 204, S279-S283. https://doi.org/10.1093/infdis/jir216

[11] Murakami, H., Van Cuong, N., Van Tuan, H., Tsukamoto, K. and Hien do, S. (2008) Epidemiological Impact of a Nationwide Measles Immunization Campaign in Viet Nam: A Critical Review. Bulletin of the World Health Organization, 86, 948-955. https://doi.org/10.2471/BLT.07.048579

[12] Nmor, J.C., Thanh, H.T. and Goto, K. (2011) Recurring Measles Epidemic in Vietnam 2005-2009: Implication for Strengthened Control Strategies. International Journal of Biological Sciences, 7, 138-146. https://doi.org/10.7150/ijbs.7.138

[13] Sniadack, D.H., Mendoza-Aldana, J., Huyen, D.T., Vann, T.T., Cuong, N.V., Olive, J.M., Toda, J.M. and Hien, N.T. (2011) Epidemiology of a Measles Epidemic in Vietnam 2008-2010. The Journal of Infectious Diseases, 204, S476-S482. https://doi.org/10.1093/infdis/jir092

[14] Kien, V.D., Van Minh, H., Giang, K.B., Mai, V.Q., Tuan, N.T. and Quam, M.B. (2017) Trends in Childhood Measles Vaccination Highlight Socioeconomic Inequalities in Vietnam. International Journal of Public Health, 62, 41-49. https://doi.org/10.1007/s00038-016-0899-4

[15] Hien, N.D., Luan, L.T., Huong, N.T., Nguyen, N.A.T., Tran Hong, T., Nguyen, X.H., Le Quoc, H., Duan Huy, H., Dao Xuan, V., Dinh Hong, D., Ishikawa, S., Lee, T. and Nakayama, T. (2011) High Immunogenicity of Measles AIK-C Vaccine Produced in Vietnam. Eastern Journal of Medicine, 16, 199-207.

[16] Roberts, L. (2015) In Vietnam, an Anatomy of a Measles Outbreak. Science, 348, 962. https://doi.org/10.1126/science.348.6238.962

[17] Toda, K., Reef. S., Tsuruoka, M., Iijima, M., Dang, T.H., Duong, T.H., Nguyen, V.C. and Nguyen, T.H. (2015) Congenital Rubella Syndrome (CRS) in Vietnam 2011-2012-CRS Epidemic after Rubella Epidemic in 2010-2011. Vaccine, 33, 3673-3677. https://doi.org/10.1016/j.vaccine.2015.06.035

[18] Zen, Y.H., Shih, C.T., Kung, W.J., Lee, C.H. and Lin, C.C. (2017) Rubella Immunity in Pregnant Native Taiwanese and Immigrants from Asian Countries. The American Journal of Tropical Medicine and Hygiene, 96, 411-414. https://doi.org/10.4269/ajtmh.16-0528

[19] Li, C.S., Yang, Y.Y., Wang, J.G., Zhu, Z., Tang, W., Li, Z., Sun, X.D. and Xu, W.B. (2012) Molecular Epidemiological Analysis of Rubella Virus Isolates from 2001 to 2011 in Shanghai, China. Chinese Journal of Virology, 28, 124-129. (In Chinese)

[20] CDC (2013) Nationwide Rubella Epidemic_Japan, 2013. $M M W R, 62,457-462$. 
[21] Pham, V.H., Nguyet, D.P., Mai, K.N., Truong, K.H., Huynh, L.V., Pham, T.H. and Abe, K. (2014) Measles Epidemics among Children in Vietnam: Genomic Characterization of Virus Responsible for Measles Outbreak in Ho Chi Minh City, 2014. EBioMedicine, 1, 133-140. https://doi.org/10.1016/j.ebiom.2014.10.015

[22] Hinman, A.R., Irons, B., Lewis, M. and Kandola, K. (2002) Economic Analyses of Rubella and Rubella Vaccines: A Global Review. Bulletin WHO, 80, 264-270.

[23] Babigumira, J.B., Morgan, I. and Levin, A. (2013) Health Economics of Rubella: A Systematic Review to Assess the Value of Rubella Vaccination. BMC Public Health, 13, 406. https://doi.org/10.1186/1471-2458-13-406

[24] Thompson, K.M. and Odahowski, C.L. (2016) The Costs and Valuation of Health Impacts of Measles and Rubella Risk Management Policies. Risk Analysis, 36, 1357-1382. https://doi.org/10.1111/risa.12459

[25] Jadhav, S., Gautam, M. and Gairola, S. (2014) Role of Vaccine Manufacturers in Developing Countries towards Global Healthcare by Providing Quality Vaccines at Affordable Prices. Clinical Microbiology and Infection, 20, 37-44.

https://doi.org/10.1111/1469-0691.12568 